\title{
Imported leishmaniasis in travelers: a 7-year retrospective from a Parisian hospital in France
}

\author{
Nesrine Aissaoui', Samia Hamane ${ }^{1}$, Maud Gits-Muselli ${ }^{1,2}$, Antoine Petit ${ }^{3}$, Mazouz Benderdouche ${ }^{1}$, \\ Blandine Denis ${ }^{4}$, Alexandre Alanio ${ }^{1,2}$, Sarah Dellière ${ }^{1,2}$, Martine Bagot ${ }^{3,5}$ and Stéphane Bretagne $e^{1,2^{*}}$
}

\begin{abstract}
Background: Leishmaniases are regularly seen in non-endemic areas due to the increase of international travels. They include cutaneous leishmaniases (CL) and mucocutaneous (MC) caused by different Leishmania species, and visceral leishmaniases $(\mathrm{VL})$ which present with non-specific symptoms.
\end{abstract}

Methods: We reviewed all consecutive leishmaniasis cases seen between September 2012 and May 2020. The diagnostic strategy included microscopy after May-Grünwald-Giemsa staining, a diagnostic quantitative PCR (qPCR) assay, and species identification based on sequencing of the cytochrome $b$ gene.

Results: Eighty-nine patients had a definitive leishmaniasis diagnosis. Nine patients had VL with Leishmania infantum. Eighty patients had CL. Twelve patients acquired CL after trips in Latin America (7 Leishmania guyanensis, 2 Leishmania braziliensis, 2 Leishmania mexicana, and 1 Leishmania panamensis). Species could be identified in 63 of the $68 \mathrm{CLS}$ mainly after travel in North Africa (59\%) with Leishmania major (65\%), Leishmania tropica/killicki (24\%), and L. infantum $(11 \%)$, or in West Sub-Saharan Africa (32\%), all due to L. major. The median day between appearance of the lesions and diagnosis was 90 [range 60-127].

Conclusions: Our diagnostic strategy allows both positive diagnoses and species identifications. Travelers in West Sub-Saharan Africa and North Africa should be better aware of the risk of contracting leishmananiasis.

\section{Highlights}

- Imported leishmaniases are regularly seen in non-endemic areas.

- Cutaneous forms are due to different species that need to be correctly identified for adapting treatment and epidemiologic purposes.

- The index of suspicion for the visceral form is often low because of the non-specificity of the clinical symptoms and the notion of travel in endemic areas often remote.

- The strategy, based on diagnostic quantitative PCR followed by sequencing for species identification, allows for rapid and safe diagnoses in a routine laboratory.

\footnotetext{
*Correspondence: stephane.bretagne@aphp.fr

${ }^{1}$ Laboratoire de Parasitologie et de Mycologie, Hôpital Saint-Louis,

Assistance Publique-Hôpitaux de Paris (AP-HP), 1 Avenue Claude

Vellefaux, 75475 Paris, France

Full list of author information is available at the end of the article
} 
Keywords: Cutaneous leishmaniasis, Visceral leishmaniasis, Quantitative PCR, Cytochrome b sequencing, Leishmania major, Leishmania tropica, Leishmania infantum

\section{Introduction}

Leishmaniases are zoonotic and anthroponotic diseases caused by several protozoan species in the genus Leishmania that are transmitted by the bites of phlebotomine sand flies. They represent a major public health problem in endemic countries, with regular increases reported in the past decade [1-3]. Different species present with diverse clinical symptoms, with a certain degree of specificity in the clinical presentation depending on the species [4]. Leishmaniases are thus classified into cutaneous $(\mathrm{CL})$, mucocutaneous (MC), and visceral leishmaniases (VL) $[5,6]$.

Whereas VL in non-endemic areas is usually seen in immunocompromised adult patients living or having lived in endemic areas, imported CLs are easily linked to international travels. In recent years, these imported CLs have been on the rise due to international tourism, military operations, and the influx of immigrants from endemic countries [7-9]. The French National Reference Centre reported a stable number of cases until 2012 [10], but now reports an annual increase in CL declarations, from 130 in 2013-2017 to 214 in 2018, mostly (90\%) from North Africa (https://cnr-leish.edu.umontpellier.fr/files/ 2019/05/Rapport_CNRLeishmanioses_Act-2018.pdf). We were therefore interested in analyzing the data collected in our hospital located in northeast Paris.

We were also interested in validating our two-step diagnostic strategy, which includes a real-time quantitative PCR (qPCR) assay for the positive diagnosis targeting the consensus sequence of the highly repeated kinetoplast DNA, followed by the amplification and sequencing of a cytochrome $b(c y t b)$ gene fragment for species identification [11]. Indeed, the species identification step is necessary for making the best therapeutic decisions according to species [5,6]. If VL is mainly due to Leishmania infantum, different species can be responsible for CL in both Latin America and the Mediterranean basin, and they have different progressions and treatment options $[3,12]$.

\section{Patients and methods}

\section{Patients and sample processing}

All patients with a positive leishmaniasis diagnosis seen in our laboratory at Saint-Louis Hospital in Paris, France between 1 September 2012 and 31 May 2020 were included. Clinical and epidemiological data, including the age, gender, country visited, length of stay, date of return, date of lesion(s) onset, clinical aspect, and anatomical site of the lesions, were collected, as were the treatments.
Skin scrapings or biopsies were performed by clinical microbiologists skilled in the diagnosis of CL. Thin smears were examined under a microscope after MayGrünwald-Giemsa staining. For VL, DNA was extracted from all specimens requested by the clinicians (i.e., bone marrow, blood, and/or tissue biopsies) using the QiA Symphony extraction kit (QIAGEN, Germany) following the manufacturer protocol. The molecular investigations have been previously described [11]. Briefly, a Leishmania diagnosis was confirmed by qPCR amplification of a 152-bp fragment of $18 \mathrm{~S}$ rRNA. The quantitative results are expressed in the quantification cycle $(\mathrm{Cq})$, with DiaControlDNA CY (Diagenode Diagnostics, Liège, Belgium) used as an internal control (IC). The presence of PCR inhibitors is excluded when the difference between the IC expected Cq value and the clinical sample IC Cq value is $<3$. Additionally, the quantity of sampled human cells is checked by amplification and comparison with the single-copy human albumin gene. As previously proposed for the diagnosis of pneumocystosis [13], the number of human cells was considered sufficient if there were $\geq 1000$ copies $/ \mathrm{mL}$ of albumin DNA.

\section{Species identification}

Species identification was performed by sequencing an $872 \mathrm{bp}$ fragment of the $c y t b$ gene using two sets of primers as previously described [11]. The sequences were aligned and analyzed using the Geneious multiple sequence-alignment program and compared with reference sequences in the GenBank database using the BLAST algorithm. Single nucleotide polymorphisms (SNPs) were identified and numbered according to previously described SNPs [11].

\section{Statistical analyses}

Statistical analyses were performed using SPSS 24 software (SPSS Inc, Armonk, NY). The Pearson chi-square test was used to compare variables with a confidence of 0.95 .

\section{Results}

Leishmaniasis diagnosis and species identification

Overall, 292 and 662 patients were tested for a suspicion of $\mathrm{CL}$ and $\mathrm{VL}$, respectively, during the study period. We obtained 89 Leishmania-positive samples, 80/292 (27.4\%) for CL and 9/662 (1.35\%) for VL. For 76 of the $89(85.4 \%)$ positive samples, the diagnosis was made by microscopy showing the presence of amastigote forms 
on thin smears, while 13 of 89 (14.6\%) samples (11 CLs and $2 \mathrm{VLs}$ ) were qPCR-positive only. The sensitivity of the microscopic examination compared to qPCR in our study was $86 \%$ (69/80) for CL and 78\% (7/9) for VL. The samples with negative microscopic examinations had low parasitic loads $(\mathrm{Cq} \geq 29)$. A $\mathrm{Cq} \geq 29$ was associated with a negative direct examination in $41 \%(11 / 27)$ of the $\mathrm{CL}$ samples and $50 \%(2 / 4)$ of the VL samples.

Identification was successful for all VLs $(n=9)$ and CLs from Latin America $(n=12)$, but failed for 7\% (5/68) of the CLs from the Old World. The presence of PCR inhibitors to explain these failures was excluded, as was a lack of sufficient clinical material (at least $10^{3}$ human cells/sample). The failed identifications were attributed to insufficient parasitic loads in the samples. Indeed, the five failures were all among the 32 samples with a $\mathrm{Cq}>29$, and all were sampled more than 90 days after the initial skin lesions appeared.

\section{Clinical presentation Patients with VL}

Nine patients had VL; all were men, aged from 2 to 73 years. All the patients had a prolonged stay in an $L$. infantum-endemic country (Algeria, $\mathrm{n}=5$; French Mediterranean seashore, $n=2$; Republic of Georgia (South Caucasia), $n=1$; and Spain, $n=1$ ). Seven of the patients had known immunodepression (AIDS, $\mathrm{n}=3$; lymphoma, $\mathrm{n}=3$; vasculitis, $\mathrm{n}=1$ ). The other two were a 50 -year-old man lost to follow-up and a 2-year-old boy with pancytopenia, who was hospitalized for suspicion of leukemia after a travel in south-eastern Spain (Alicante region). All were treated with liposomal amphotericin B. Three patients with unsolved immunodepression had recurrences of circulating Leishmania DNA. Of the seven patients with known outcome, two died (one patient with AIDS and one patient with lymphoma).

The only species identified in VL was L. infantum. Seven sequences perfectly matched the Greek reference strain (L. infantum MCAN/GR/94/CRE69: GenBank access number 156 EF579913) and the Tunisian reference sequence (L. infantum MHOM/TN/80/IPT1: GenBank 157 access number EF579895).The remaining two sequences had a previously identified C779T synonymous SNP (His-His) [11].

\section{Patients with Latin American CL (Table 1)}

Twelve patients ( 9 men, 3 women; mean age $45 \pm 14$ years) were diagnosed with CL after trips in Latin America. The cutaneous lesions were all on exposed skin and consisted of seven exudative ulcers and five crusty skin lesions without mucosal involvement. All were positive on microscopy examination. The identified species were 7 Leishmania guyanensis $(\mathrm{n}=7)$, 2 Leishmania braziliensis $(\mathrm{n}=2)$, Leishmania mexicana $(\mathrm{n}=1)$, and Leishmania panamensis $(\mathrm{n}=1)$. The mean delay between lesion appearance and medical advice was $79 \pm 38$ days, with no differences between the species involved. When present, the DNA sequences showed synonymous mutations (Table 1). Treatment protocols were in accordance with consensual recommendations [6]. No patients developed mucosal lesions.

\section{Patients with Mediterranean CL}

Cutaneous leishmaniasis from the Mediterranean basin was diagnosed in 68 patients (median age: 46 years, range 1-83; 43 males, 25 females). In 88\% (60/68) of the cases, the patients were of African origin and travelled regularly to their or their relatives' native countries during summer vacation. The patients aged $<30$-years-old $(n=26)$ were mainly born in non-endemic areas $(69 \% ; 18 / 26)$, while those $\geq 30$-years-old $(n=42)$ were primarily $(88 \%$; 37/42) long-term residents in France who were born in endemic areas. The median length of stay in the endemic region was 84 days (range 20-365 days). When the information was available, the cutaneous lesions appeared either during their stay $(33 \% ; 18 / 54)$ or within a month of their return from the endemic area $(37 \% ; 20 / 54)$. However, the median day between appearance of the lesions and diagnosis was 90 [60-127]. Thus, despite the usual onset of lesions within a month of returning, most of the patients delayed seeking medical advice for more than two months after the return from endemic area.

The most frequently visited regions associated with CL were North Africa [Tunisia, $\mathrm{n}=25$ (more specifically the Tataouine region $\mathrm{n}=8$ ); Morocco, $\mathrm{n}=8$; Algeria, $\mathrm{n}=6$ ] and West Sub-Saharan Africa (Senegal, $\mathrm{n}=11$; Mauritania, $\mathrm{n}=7$; Mali, $\mathrm{n}=3$ ). We also had cases imported from the Middle East (Israel $n=3$, with 2 children in the same family; Egypt, $\mathrm{n}=1$ ), and Southern Europe (Spain $\mathrm{n}=3$; Italy $\mathrm{n}=1$ ).

Three species were identified in 93\% (63/68) of the patients. The sequencing failed in 5 patients ( 2 from Algeria and 1 each from Mauritania, Spain, and Italy) and corresponded with those showing a low parasitic burden in skin lesions that had lasted more than 90 days. Leishmania major was by far the most frequent 
Table 1 Main clinical features of the Latin America leishmaniasis cases and results of sequencing of the cytochrome $b$ fragment

\begin{tabular}{|c|c|c|c|c|}
\hline & L. guyanensis $\mathrm{n}=7$ & L. braziliensis $\mathrm{n}=2$ & L. mexicana $\mathrm{n}=2$ & L. panamensis $\mathrm{n}=1$ \\
\hline \multicolumn{5}{|l|}{ Visited country } \\
\hline Bolivia & - & 1 & - & - \\
\hline Costa Rica & - & - & - & 1 \\
\hline French Guiana & 5 & - & - & - \\
\hline Mexico & - & - & 2 & - \\
\hline Peru & 2 & 1 & - & - \\
\hline \multicolumn{5}{|l|}{ Length of stay } \\
\hline$<30$ days & 6 & 1 & 1 & 1 \\
\hline 30-90 days & - & 1 & - & - \\
\hline$>90$ days & 1 & - & 1 & - \\
\hline \multicolumn{5}{|l|}{ Occurrence of skin lesions } \\
\hline$<30$ days after return & 5 & 2 & 1 & - \\
\hline 30-100 days after return & 2 & - & 1 & 1 \\
\hline \multicolumn{5}{|l|}{ Delay for seeking medical assistance } \\
\hline$\leq 90$ days & 3 & 2 & & 1 \\
\hline$>90$ days & 4 & & 2 & \\
\hline Exudative lesions & 4 & 2 & 0 & 1 \\
\hline \multicolumn{5}{|l|}{ Treatment $^{\mathrm{a}}$} \\
\hline Pentamidine & 4 & - & - & 1 \\
\hline Intralesional meglumine antimoniate & - & $1^{\mathrm{b}}$ & 1 & - \\
\hline Liposomal amphotericin B & 2 & $1^{\mathrm{b}}$ & - & - \\
\hline Itraconazole & $1^{\mathrm{c}}$ & - & - & - \\
\hline \multicolumn{5}{|l|}{ Cytochrome b sequencing } \\
\hline Reference sequence GeneBank access number & AB095969.1 & LC472861.1 & AB095963.1 & MK570510 \\
\hline SNP & Absence & Absence & $\begin{array}{l}\text { C53T (Met-> Thr) and } \\
\text { A584G (Gln-> Gln) }\end{array}$ & absence \\
\hline
\end{tabular}

a Two patients ( 1 L. braziliensis and 1 L. mexicana) were included in therapeutic trials in another hospital

${ }^{\mathrm{b}}$ Same patient treated with an association intralesional meglumine antimoniate and liposomal amphotericin $\mathrm{B}$

c Patient treated with itraconazole because of previous treatment with pentamidine in South America

(48/63; 76\%) species identified, followed by L. tropica/ killicki $(9 / 63 ; 14 \%)$, and L. infantum $(6 / 63 ; 10 \%)$.

The median length of stay in the endemic regions was 60 days (range 20-365 days), with no significant differences between the three species (Table 2). Because the journeys to endemic areas mainly took place during summer vacation, the monthly distribution of the CL diagnoses in our center was between October and February $(n=47)$, with a peak in January $(n=16)$.

The correspondence of the morphological aspects of the CL lesions to the identified species is illustrated in Fig. 1 . When more specifically comparing $L$. major and L. tropica/killicki, the clinical lesions from L. major were more often crusted and ulcero-necrotic (44/48 [97\%] vs 6/9 [67\%]; $p=0.036)$ and more often localized on the limbs than on the face $(\mathrm{p}=0.004)$. Although the $L$. major lesions tended more often to be multiple (62\%; 29/47) than the L. tropica/killicki lesions (44\%; 4/9), the difference was not statistically significant, nor was the delay in seeking medical assistance (Table 2).

The sequenced portion of the cytb gene of CLs caused by $L$. infantum was identical to the sequences of the VL cases. Sequences identified as L. tropica $(\mathrm{n}=3$, imported from Tunisia and Morocco) matched with two reference strains [L. tropica $\mathrm{MHOM} / \mathrm{SU} / 58$ / Strain OD (GenBank access number AB095960) and L. tropica MHOM/SU/74/K27 (World Health Organization reference strain of L. tropica, GenBank access number HQ908270.1 and KY360314.1)] with a query cover exceeding 99\%. The 6 sequences identified as $L$. killicki, all from Tunisia, matched the $L$. killicki reference strain MHOM/TN/86/LEM163 (GenBank access number AB434676) with a query cover exceeding $99 \%$. The $48 \mathrm{~L}$. major sequences had a query cover exceeding $99 \%$. with the $L$. major reference strain (GenBank access number AB095961). Among them, the 20 sequences from the patients who 
Table 2 Clinical and epidemiologic characteristics of the 63 (out of 68) Mediterranean CL patients for who the Leishmania species was identified

\begin{tabular}{|c|c|c|c|}
\hline & L. major $\mathrm{n}=48(76 \%)$ & $\begin{array}{l}\text { L. tropica/killicki } \mathrm{n}=9 \\
(14 \%)\end{array}$ & L. infantum $n=6(10 \%)$ \\
\hline Median age years [IQ25-|Q75] & $39[16.3-56.5]$ & $42[12-57]$ & $56[22-56]$ \\
\hline Sex ratio (M/F) & 1.66 & 1.25 & 2 \\
\hline Median length of stay in endemic area days [IQ25-IQ75] & $60[30-90]$ & $60[48-60]$ & $45[30-75]$ \\
\hline \multicolumn{4}{|l|}{ Occurrence of skin lesions (n/data available) } \\
\hline During the stay & $12 / 38(32 \%)$ & $2 / 8(25 \%)$ & $2 / 4(50 \%)$ \\
\hline$\leq 30$ days after the return & $16 / 38(42 \%)$ & $2 / 8(25 \%)$ & $1 / 4(25 \%)$ \\
\hline$>1$ to $\leq 3$ months & $8 / 38(21 \%)$ & $3 / 8(37 \%)$ & $0 / 4(0 \%)$ \\
\hline$>3$ months & $2 / 38(5 \%)$ & $1 / 8(13 \%)$ & $1 / 4(25 \%)$ \\
\hline Median days before seeking medical advice [IQ25-IQ75] & 90 [60-103] & $90[90-12]$ & $180[128-255]$ \\
\hline \multicolumn{4}{|l|}{ Number of lesions (n/data available) } \\
\hline Unique & 18/47 (38\%) & $5 / 9(56 \%)$ & $3 / 6(50 \%)$ \\
\hline Multiple & $29 / 47(62 \%)$ & $4 / 9(44 \%)$ & $3 / 6(50 \%)$ \\
\hline \multicolumn{4}{|l|}{ Localization of lesions (n/data available) } \\
\hline Limb (at least one lesion) & $37 / 46(80 \%)$ & $3 / 9(33 \%)$ & $3 / 6(50 \%)$ \\
\hline Face (at least one lesion) & $9 / 46(20 \%)$ & $6 / 9(67 \%)$ & $3 / 6(50 \%)$ \\
\hline Crusted ulcero-necrotic lesions & $44 / 48(92 \%)$ & $6 / 9(67 \%)$ & $1 / 6(17 \%)$ \\
\hline \multicolumn{4}{|l|}{ Country of contamination } \\
\hline North-Africa $(n=37)$ & $24 / 37(65 \%)$ & 9/37 (24\%) & 4/37 (11\%) \\
\hline Algeria $(n=4)$ & $2 / 4$ & - & $2 / 4$ \\
\hline Morocco $(n=8)$ & $4 / 8$ & $2 / 8$ & $2 / 8$ \\
\hline Tunisia $(n=25)$ & $18 / 25$ & $7 / 25$ & - \\
\hline Sub-Saharan Africa $(n=20)$ & $20 / 20(100 \%)$ & - & - \\
\hline Mali $(n=3)$ & $3 / 3$ & - & - \\
\hline Mauritania $(n=6)$ & $6 / 6$ & - & - \\
\hline Senegal $(n=11)$ & $11 / 11$ & - & - \\
\hline Middle East $(n=4)$ & $4 / 4(100 \%)$ & - & - \\
\hline Egypt $(n=1)$ & $1 / 1$ & - & - \\
\hline Israel $(n=3)$ & $3 / 3$ & - & - \\
\hline Europe $(n=2)$ & - & - & $2 / 2(100 \%)$ \\
\hline Spain $(n=2)$ & - & - & $2 / 2$ \\
\hline
\end{tabular}

travelled to Sub-Saharan Africa had an A108G synonymous mutation (Val-Val) compared with the L. major strain (GenBank access number AB095961) reference sequence, that was not observed in the other patients. In addition, a C624T synonymous mutation (ArgArg) was observed in all $(24 / 24)$ the L. major strains from patients who travelled in North Africa (Algeria, Morocco, and Tunisia), which was not present in the sequences from those who returned from Sub-Saharan Africa (20) or in three of the four patients from the Middle East. Among these later, one Israeli patient had professional travels in a lot of countries of the Mediterranean basin and a precise location for the infection could not be assessed.

\section{Discussion}

We report on a comprehensive collection of 89 leishmaniasis cases seen over more than 7 consecutive years in a university hospital located in Paris, France. These cases consisted of 77 Old World and 12 New World Leishmania cases. The cohort primarily included CLs from North Africa (39 cases) or West Sub-Saharan Africa (21 cases).

Diagnostic qPCR targeting the $18 \mathrm{~S}$ rRNA gene [11] was more sensitive than microscopy for routine diagnosis, as has already been shown using other PCR gene targets and methods for CL [14] and New World Leishmania spp. [15]. Besides the closed tube format to avoid contamination with amplicons and thus false positive results, the main interest in $\mathrm{qPCR}$ is to exclude false negative results 


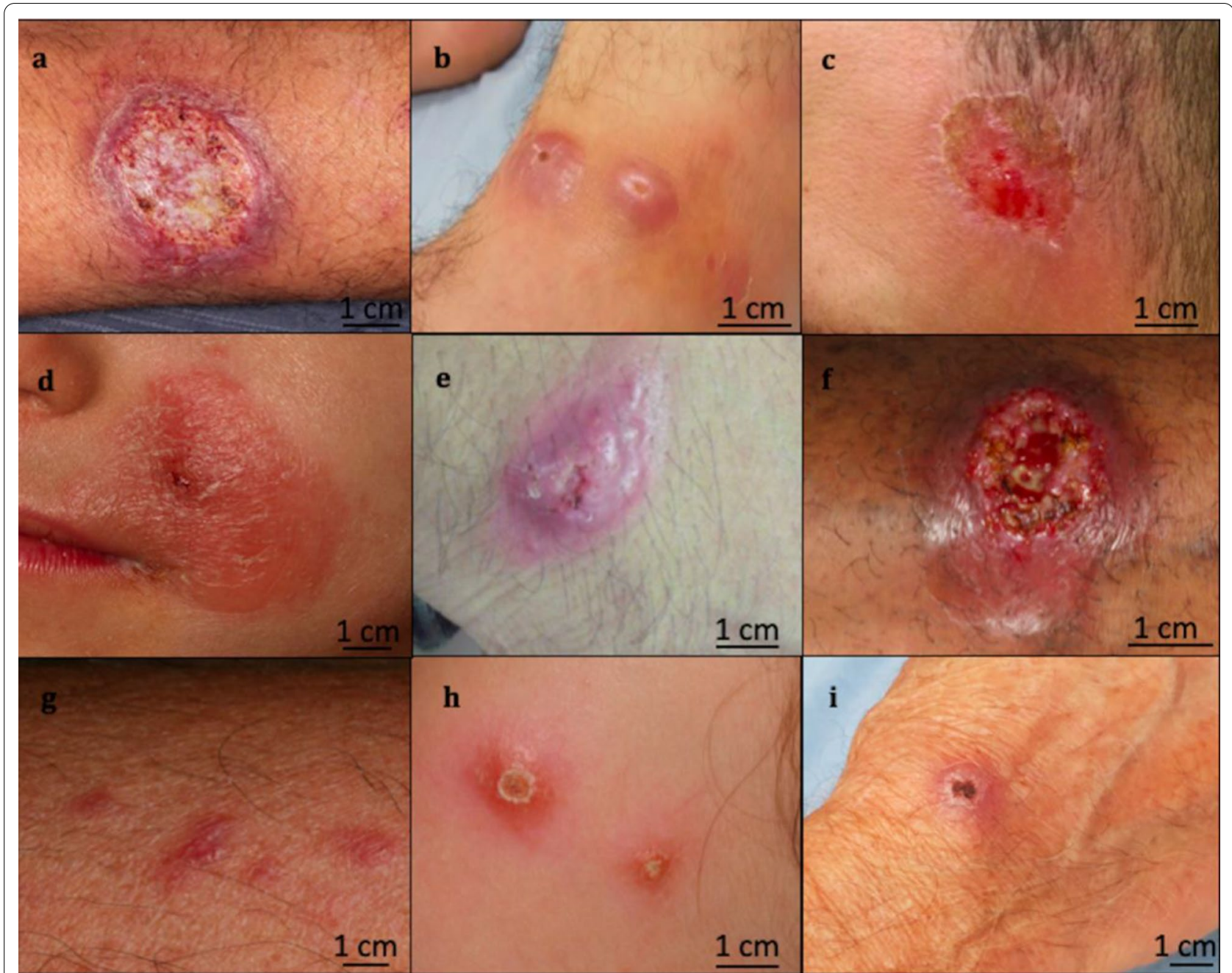

Fig. 1 Clinical appearance of Mediterranean cutaneous leishmaniasis lesions according to the identified species showing the clinical polymorphism. Leishmania major: a typical crusty'pizza-like' lesion; b atypical erythemato-papulous lesions; $\mathbf{c}$ atypical inflammatory lesion. Leishmania tropica/killicki: $\mathbf{d}$ typical face-located lesion; $\mathbf{e}$ and $\mathbf{f}$ atypical limb-located inflammatory lesions. Leishmania infantum: $\mathbf{g}$ and $\mathbf{h}$ typical inflammatory lesions; $\mathbf{i}$ atypical crusty lesion. Please note that the scale used in this figure is approximate

by accurately quantifying the parasitic load and determining if PCR inhibitors are present [16]. We confirmed that a CL diagnosis could be corrected when microscopy was negative, even when the lesions appeared old and were healing either spontaneously or due to previous treatment. For VL diagnoses, a more sensitive tool than microscopy is crucial for proper diagnosis and follow up.

A different target was chosen for the identification step than for the diagnostic step, namely the $c y t b$ gene, as previously proposed for Leishmania sp. identification [17]. This precaution was designed to limit false positives caused by routine laboratory contamination. Indeed, opening amplicon-containing tubes for secondary analyses such as sequencing leads to a risk of contamination from the laboratory environment. Moreover, in contrast with non-sequence-based methods such as ITS-RFLP (internal transcribed spacer region-restriction fragment length polymorphisms), sequencing identifies SNPs that can be useful for comparison with databases [18]. This target also allows for the correct identification of L. killicki within the heterogeneous L. tropica complex [19]. However, the number of copies of the cytb gene $(\sim 50$ [17]) is less than that of the 18S rRNA gene $(\sim 50-200$ [20]), explaining why species identification failed for five samples with low parasite loads.

For VL occurring in non-endemic areas, the issue is to increase the suspicion index and confirm the diagnosis using qPCR [21]. Indeed, the clinical presentation is not specific and can be seen in different situations of immunosuppression such as HIV infection [22], anti-TNF 
treatment [23, 24], after solid organ transplantation [25], or after hematopoietic stem cell transplantation [26]. Excepted for HIV co-infection in endemic areas [22], the prevalence of VL is often very low [23, 24]. The accepted physiopathology is the reactivation of a persistent parasite from a previous primo-infection subsequent to an acquired immunodeficiency [27]. Thus, the disappearance of circulating DNA after treatment does not mean the parasite has been cleared from the organism, hence the possible reoccurrence of the disease [22]. Conversely, detection of leishmania DNA is not synonymous of an ongoing clinical active disease [28]. Visceral leishmaniasis is also a differential diagnosis of leukemia-like syndromes in infants living or traveling to endemic countries, as observed here for a pediatric case $[29,30]$.

For CL, the travel history easily differentiates patients returning from Latin America from those returning from Africa and the Middle East. In the former, the clinical lesions are often exudative, large, and prone to secondary bacterial infections. The main goal then is species identification, and we indeed identified different species, in accordance with the wealth of Leishmania spp. in this region $[31,32]$. Importantly, none of the cases presented with mucosal lesions, confirming that patients seek medical advice soon enough after the appearance of such lesions. The treatments were diverse, according to patient and species (Table 1), but effective for all patients.

The largest contingent of patients with CL in our series was composed of migrants or French citizens born in France visiting relatives in North Africa or West SubSaharan countries. The delay between the appearance of lesions and the microbiological diagnosis was more than 3 months, which suggests these patients only consult when no spontaneous healing occurs. Consequently, the actual burden of CL is probably grossly underestimated. Three species responsible for the Old World CLs were identified: L. infantum, L. tropica/killicki, and $L$. major. Our clinical observations support previous studies reporting that lesions caused by $L$. major are more often multiple and located on limbs, whereas lesions due to L. tropica are usually single and face-localized [33]. These differences can be explained by the different vector behaviors [33]. Clinically, the L. major lesions were more exudative and wet than the L. tropica/killicki lesions, while the L. infantum lesions were more nodular infiltrative. Despite these clinical differences, however, there were numerous overlaps, and it is not possible to exclude a given species based on its clinical aspect. Moreover, the distribution areas of the species also frequently overlap [3]. This highlights the importance of molecular identification for both epidemiological purposes and to avoid misdiagnosing L. infantum CL, which can lead to secondary VL [34], or alternatively, to reinsure patients in cases of L. major lesions, which do not disseminate in the case of HIV infection [11].

The age distribution of the Old World CL cases showed a double peak, corresponding to children and adults, including the elderly. While the occurrence of CL is not surprising in naive children born in a non-endemic area, the occurrence of CL in older people suggests either they were naïve because (i) the parasite was not contracted during childhood, (ii) the patients lost their immune status after long periods spent in France, or (iii) that previous exposure to the parasite is not in any way protective. Mandall et al. suggest that despite the induction of a protective immune response, secondary $L$. major infections can effectively establish themselves in a previously infected host, supporting the non-protective hypothesis [35]. Moreover, Bousslimi et al. have reported cases of CL not just in Tunisian children, but also in Tunisian adults (57.1\%), which also supports the non-protective scenario [33]. In this series, one can underline the high number of CL cases after travel to south-eastern Tunisia (governorate of Tataouine), where both $L$. major and L. tropica/ killicki are endemic [33]. This continual transmission of $\mathrm{CL}$ relates to environmental changes, which impact mammal reservoirs and sand fly populations, as well as demographic and human behavioral factors [36], factors specifically present in Tataouine [3].

Data on the molecular identification of Leishmania species from West Sub-Saharan Africa are scanty although numerous outbreaks have been reported, mainly based on serology surveys or clinical diagnoses [37]. In a recent study, 8 cases of $L$. major infections were reported from Mali using an end-point PCR assay [38]. Here, we added 20 confirmed $L$. major infections from West Sub-Saharan Africa. In accordance with the absence of L. tropica and L. infantum CL in this region, only L. major was reported [37]. Interestingly, we observed two synonymous mutations in the cytb gene (A108G and C624T) that distinguished the L. major cases from West Sub-Saharan Africa from those from North Africa and the Middle East. Using an isoenzyme analysis, a particular zymodeme (MON26) reported in Mauritania, Senegal, and Mali has previously been shown to differ from the common zymodeme (MON 25) from North Africa [39]. If our results are confirmed, this observation could serve as an epidemiological marker that is easily available using PCR.

We readily acknowledge the limits of our observational study to draw any epidemiological conclusions based on the frequency and intensity of transmission in the visited countries. We have no data on healthy returning travelers or those with self-limited and/or spontaneously healing lesions who did not seek medical advice. In addition, we cannot exclude that word-of-mouth information led to patients coming to consult in our hospital specifically, 
leading to a false impression of an increase in cases from a specific region.

\section{Conclusion}

The risk of contracting leishmaniasis should be more widely known, specifically for patients of African origin visiting relatives who may believe themselves to be immune to these diseases. Indeed, while some lesions are limited and heal easily, others can be extensive with definite unaesthetic scars after healing. Since there are no current vaccines or prophylaxis recommendations, the only preventive measure is to reduce contact with sand flies by using personal protective measures such as avoiding outdoor activities, wearing protective clothing, and applying insect repellent when sand flies are most active. Sleeping in air-conditioned or well-screened areas may be a formal recommendation, but in low-income countries, fans or ventilators might be more affordable, and they do considerably inhibit the movement of sand flies, which are weak fliers [7].

From a laboratory point of view, our diagnostic strategy enables both a positive diagnosis and an accurate species identification [11]. For VL, a more systematic use of qPCR should be implemented in cases of unexplained fever in immunocompromised patients that have lived or travelled in endemic areas [21]. The species identification available using expensive equipment in the laboratories in high-income countries can be useful in identifying Leishmania species from countries where information is currently lacking $[31,40]$.

\section{Acknowledgements}

We are grateful to all the clinicians who cared after the patients and the technicians for their involvement in the biological diagnosis.

\section{Disclaimers}

No conflict of interest to be declared for the present study.

\section{Authors' contributions}

NA: data collection and curation, writing; SH: data collection, laboratory diagnosis. MB: data collection, clinical diagnosis; AP: patient diagnosis and treatment, reviewing; MG: data collection, laboratory diagnosis; BD: patient diagnosis and treatment, reviewing; AA: conceptualization, methodology, reviewing; SD: conceptualization, methodology, reviewing; $M B$ : patient diagnosis and treatment, reviewing and editing; SB: conceptualization, methodology, writing, reviewing and editing. All authors read and approved the final manuscript.

\section{Funding}

This research did not receive any specific grant and was performed on the routine base of the laboratory. This work was performed with the results obtained through our routine diagnosis process and did not benefit from a specific funding.

\section{Availability of data and materials}

All the data and materials are included in the manuscript.

\section{Declarations}

Ethics approval and consent to participate

This was a retrospective non-interventional analysis that had no impact on standard clinical procedures and no additional biological sampling following the physicians' prescriptions for optimal treatment. Clinical data were anonymized before the analysis. French Health Public Law (CSP Art L1121-1.1) states that such a protocol does not require ethical approval and is exempt from informed consent procedures. All methods were performed in accordance with the relevant guidelines and regulations.

\section{Consent for publication}

Signed informed consent was obtained for the photographs.

\section{Competing interests}

The authors report no conflicts of interest. The authors alone are responsible for the content and the writing of the paper.

\section{Author details}

${ }^{1}$ Laboratoire de Parasitologie et de Mycologie, Hôpital Saint-Louis, Assistance Publique-Hôpitaux de Paris (AP-HP), 1 Avenue Claude Vellefaux, 75475 Paris, France. ${ }^{2}$ Université de Paris, Paris, France. ${ }^{3}$ Service de Dermatologie, Hôpital Saint-Louis, Assistance Publique-Hôpitaux de Paris (AP-HP), Paris, France.

${ }^{4}$ Département de Maladies Infectieuses, Hôpital Saint-Louis, Assistance

Publique-Hôpitaux de Paris (AP-HP), Paris, France. ${ }^{5}$ INSERM U976, Paris, France.

Received: 10 May 2021 Accepted: 19 August 2021

Published online: 15 September 2021

\section{References}

1. Okwor I, Uzonna J. Social and economic burden of human leishmaniasis. Am J Trop Med Hyg. 2016;94:489-93.

2. Karimkhani C, Wanga V, Naghavi P, Dellavalle RP, Naghavi M. Global burden of cutaneous leishmaniasis. Lancet Infect Dis. 2017;17:264.

3. Aoun K, Bouratbine A. Cutaneous leishmaniasis in North Africa: a review. Parasite. 2014;21:14.

4. Burza S, Croft SL, Boelaert M. Leishmaniasis. Lancet. 2018;392:951-70.

5. Hodiamont CJ, Kager PA, Bart A, de Vries HJC, van Thiel PPAM, Leenstra T, et al. Species-directed therapy for leishmaniasis in returning travellers: a comprehensive guide. Ghedin E, editor. PLoS Negl Trop Dis. 2014;8:e2832.

6. Blum J, Buffet P, Visser L, Harms G, Bailey MS, Caumes E, et al. LeishMan recommendations for treatment of cutaneous and mucosal leishmaniasis in travelers, 2014. J Travel Med. 2014;21:116-29.

7. Mansueto P, Seidita A, Vitale G, Cascio A. Leishmaniasis in travelers: a literature review. Travel Med Infect Dis. 2014;12:563-81.

8. Pavli A, Maltezou HC. Leishmaniasis, an emerging infection in travelers. Int J Infect Dis. 2010;14:e1032-9.

9. Boggild AK, Caumes E, Grobusch MP, Schwartz E, Hynes NA, Libman M, et al. Cutaneous and mucocutaneous leishmaniasis in travellers and migrants: a 20-year GeoSentinel Surveillance Network analysis. J Travel Med. 2019;26:e1032.

10. Lachaud L, Dedet JP, Marty P, Faraut F, Buffet P, Gangneux J-P, et al. Surveillance of leishmaniases in France, 1999 to 2012. Eurosurveillance. 2013;18:20534.

11. Foulet F, Botterel F, Buffet P, Morizot G, Rivollet D, Deniau M, et al. Detection and identification of Leishmania species from clinical specimens by using a real-time PCR assay and sequencing of the cytochrome $B$ gene. J Clin Microbiol. 2007;45:2110-5.

12. Aronson N, Herwaldt BL, Libman M, Pearson R, López-Vélez R, Weina P, et al. Diagnosis and Treatment of Leishmaniasis: Clinical Practice Guidelines by the Infectious Diseases Society of America (IDSA) and the American Society of Tropical Medicine and Hygiene (ASTMH). Am J Trop Med Hyg. 2017;96:24-45.

13. Guigue N, Alanio A, Menotti J, Castro ND, Hamane S, Peyrony O, et al. Utility of adding Pneumocystis jirovecii DNA detection in nasopharyngeal aspirates in immunocompromised adult patients with febrile pneumonia. Med Mycol. 2015;53:241-7. 
14. Mesa LE, Manrique R, Muskus C, Robledo SM. Test accuracy of polymerase chain reaction methods against conventional diagnostic techniques for Cutaneous Leishmaniasis $(\mathrm{CL})$ in patients with clinical or epidemiological suspicion of CL: systematic review and meta-analysis. Chatterjee M, editor. PLoS Negl Trop Dis. Public Library of Science; 2020;14:e0007981.

15. Conter CC, Mota CA, Dos Santos BA, de Braga SL, de Terron SM, Navasconi TR, et al. PCR primers designed for new world Leishmania: a systematic review. Exp Parasitol. 2019;207:107773.

16. Bretagne S, Costa J-M. Towards a nucleic acid-based diagnosis in clinical parasitology and mycology. Clin Chim Acta. 2006;363:221-8.

17. Luyo-Acero GE, Uezato H, Oshiro M, Takei K, Kariya K, Katakura K, et al. Sequence variation of the cytochrome $b$ gene of various human infecting members of the genus Leishmania and their phylogeny. Parasitology. 2004;128:483-91.

18. Mouttaki T, Morales-Yuste M, Merino-Espinosa G, Chiheb S, Fellah $\mathrm{H}$, Martin-Sanchez J, et al. Molecular diagnosis of cutaneous leishmaniasis and identification of the causative Leishmania species in Morocco by using three PCR-based assays. Parasit Vectors. 2014;7:420-9.

19. Jaouadi K, Depaquit J, Haouas N, Chaara D, Gorcii M, Chargui N, et al. Twenty-four new human cases of cutaneous leishmaniasis due to Leishmania killicki in Metlaoui, southwestern Tunisia: probable role of Phlebotomus sergenti in the transmission. Acta Trop. 2012;122:276-83.

20. Srivastava P, Mehrotra S, Tiwary P, Chakravarty J, Sundar S. Diagnosis of Indian visceral leishmaniasis by nucleic acid detection using PCR. Snounou G, editor. PLOS ONE; 2011;6:e19304.

21. Fletcher K, Issa R, Lockwood DNJ. Visceral leishmaniasis and immunocompromise as a risk factor for the development of visceral leishmaniasis: a changing pattern at the hospital for tropical diseases, london. Schallig HDFH, editor. PLoS ONE. Public Library of Science; 2015;10:e0121418.

22. Horrillo L, Castro A, Matía B, Molina L, García-Martínez J, Jaqueti J, et al. Clinical aspects of visceral leishmaniasis caused by L. infantum in adults. Ten years of experience of the largest outbreak in Europe: what have we learned? Parasit Vectors. 2019;12:359-11.

23. Kurizky PS, Marianelli FF, Cesetti MV, Damiani G, Sampaio RNR, Gonçalves LMT, et al. A comprehensive systematic review of leishmaniasis in patients undergoing drug-induced immunosuppression for the treatment of dermatological, rheumatological and gastroenterological diseases. Rev Inst Med Trop Sao Paulo. 2020;62:e28.

24. Salmon-Ceron D, Tubach F, Lortholary O, Chosidow O, Bretagne S, Nicolas $\mathrm{N}$, et al. Drug-specific risk of non-tuberculosis opportunistic infections in patients receiving anti-TNF therapy reported to the 3-year prospective French RATIO registry. Ann Rheum Dis. 2011;70:616-23.

25. Antinori S, Cascio A, Parravicini C, Bianchi R, Corbellino M. Leishmaniasis among organ transplant recipients. Lancet Infect Dis. 2008;8:191-9.

26. Tatarelli P, Fornaro G, Del Bono V, Nicolini LA, Raiola AM, Gualandi F, et al. Visceral leishmaniasis in hematopoietic cell transplantation: case report and review of the literature. J Infect Chemother. 2018;24:990-4.

27. Bogdan C. Mechanisms and consequences of persistence of intracellular pathogens: leishmaniasis as an example. Cell Microbiol. 2008;10:1221-34.
28. Kurizky PS, Gomes CM, Cesetti MV, Martins GA, Regattieri NAT, Marianelli FF, et al. Cross-sectional screening study for Leishmania DNA and antibodies in biologic-treated patients with psoriasis living in an area endemic for leishmaniasis. Br J Dermatol. 2019;181:1337-9.

29. Koster K-L, Laws H-J, Troeger A, Meisel R, Borkhardt A, Oommen PT. Visceral Leishmaniasis as a possible reason for pancytopenia. Front Pediatr Frontiers. 2015;3:59.

30. Schwing A, Pomares C, Majoor A, Boyer L, Marty P, Michel G. Leishmania infection: misdiagnosis as cancer and tumor-promoting potential. Acta Trop. 2019;197:104855.

31. Pigott DM, Bhatt S, Golding N, Duda KA, Battle KE, Brady OJ, et al. Global distribution maps of the leishmaniases. Elife. 2014;3:e35671.

32. Correa-Cárdenas CA, Pérez J, Patino LH, Ramírez JD, Duque MC, Romero $Y$, et al. Distribution, treatment outcome and genetic diversity of Leishmania species in military personnel from Colombia with cutaneous leishmaniasis. BMC Infect Dis. 2020;20:938-1011.

33. Bousslimi N, Aoun K, Ben-Abda I, Ben-Alaya-Bouafif N, Raouane M, Bouratbine A. Epidemiologic and clinical features of cutaneous leishmaniasis in southeastern Tunisia. Am J Trop Med Hyg. 2010;83:1034-9.

34. Mouttaki T, Maksouri H, El Mabrouki J, Merino-Espinosa G, Fellah H, Itri M, et al. Concomitant visceral and localized cutaneous leishmaniasis in two Moroccan infants. Infect Dis Poverty. 2018;7:32-5.

35. Mandell MA, Beverley SM. Concomitant immunity induced by persistent leishmania major does not preclude secondary re-infection: implications for genetic exchange, diversity and vaccination. Debrabant A, editor. PLoS Negl Trop Dis. 2016;10:e0004811.

36. Kholoud K, Denis S, Lahouari B, El Hidan MA, Souad B. Management of Leishmaniases in the era of climate change in Morocco. Int J Environ Res Public Health. 2018;15:1542.

37. Sunyoto T, Verdonck K, Safi El S, Potet J, Picado A, Boelaert M. Uncharted territory of the epidemiological burden of cutaneous leishmaniasis in sub-Saharan Africa-A systematic review. Louzir H, editor. PLoS Negl Trop Dis. 2018;12:e0006914.

38. Traoré B, Oliveira F, Faye O, Dicko A, Coulibaly CA, Sissoko IM, et al. Prevalence of cutaneous leishmaniasis in districts of high and low endemicity in Mali. Boelaert M, editor. PLoS NegI Trop Dis. 2016;10:0005141.

39. Pratlong F, Dereure J, Ravel C, Lami P, Balard Y, Serres G, et al. Geographical distribution and epidemiological features of Old World cutaneous leishmaniasis foci, based on the isoenzyme analysis of 1048 strains. Trop Med Int Health. 2009;14:1071-85.

40. Zida A, Sangaré I, Nezien D, Bretagne S, Bamba S, Deniau M, et al. Mastomys natalensis, Cricetomys gambianus and Taterillus sp. were found PCR positive for Leishmania major in Burkina Faso, West Africa. Ann Parasitol. 2020;66:251-4.

\section{Publisher's Note}

Springer Nature remains neutral with regard to jurisdictional claims in published maps and institutional affiliations.

\footnotetext{
Ready to submit your research? Choose BMC and benefit from:

- fast, convenient online submission

- thorough peer review by experienced researchers in your field

- rapid publication on acceptance

- support for research data, including large and complex data types

- gold Open Access which fosters wider collaboration and increased citations

- maximum visibility for your research: over 100M website views per year
}

At BMC, research is always in progress.

Learn more biomedcentral.com/submissions 